\title{
Amateur doping: a survey on Sicilian population
}

\author{
Fabio Venturella, ${ }^{1}$ Giulia Cancellieri, ${ }^{2}$ Marco Giammanco, ${ }^{3}$ Paola Di Marco, ${ }^{2}$ Francesca Catania, ${ }^{2}$ \\ Anastasia Valentina Liga ${ }^{2}$ \\ ${ }^{1}$ Department of Biological, Chemical and Pharmaceutical Science and Technologies, University of Palermo; \\ ${ }^{2}$ Pharmacy graduate, University of Palermo; ${ }^{3}$ Department of Surgical, Oncological and Stomatological Disciplines, \\ University of Palermo, Palermo, Italy
}

\begin{abstract}
In the last years, amateur doping phenomenon has caused many victims. In order to know the diffusion of this phenomenon, we conducted an online survey thanks to Google forms. We also converted on paper the same questionnaire and we administered it in many gyms in Palermo and Trapani (Sicily, Italy). The examined sample consists of 976 people aged between 14 and 65 ( $47.3 \%$ of them are women and $52.7 \%$ are men). We asked them if they had ever taken substances to improve their athletic performances: $25.8 \%$ of them answered affirmatively and declared to take protein, amino acids, but also Ephedrine, Caffeine, Aspirin on a regular basis $(34.6 \%)$. They bought these substances in sporting stores $(32.2 \%)$, in pharmacy without prescription $(26.8 \%)$, on the Internet $(22.8 \%)$, in gyms $(10.7 \%) ; 7.5 \%$ of them answered that they bought substances in other places. Furthermore, $17.9 \%$ of them declared that training companions, but also coaches and/or responsible of sports societies, proposed them to take doping-substances (Stanazolol, Tamoxifen, Testosterone, Erythropoietin, etc.). $16.8 \%$ of interviewed claimed that it is right to take substances with the purpose to improve their performances. However,
\end{abstract}

Correspondence: Giulia Cancellieri, Pharmacy graduate, University of Palermo, Via Fortuna 5, 90151, Palermo, Italy.

Tel.: +39.3298497784.

E-mail: giulia.cancellieri@hotmail.it

Key words: Amateur doping; Sport; Adolescents; Prevention; Information.

Conflict of interest: the authors declare no potential conflict of interest.

Conference presentation: part of this paper was presented at the $91^{\text {st }}$ SIBS National Congress, Ancona, Italy, 9-10 November 2018.

Received for publication: 16 April 2019.

Revision received: 5 June 2019.

Accepted for publication: 8 June 2019.

${ }^{\circ}$ Copyright: the Author(s), 2019

Licensee PAGEPress, Italy

Journal of Biological Research 2019; 92:8238

doi:10.4081/jbr.2019.8238

This article is distributed under the terms of the Creative Commons Attribution Noncommercial License (by-nc 4.0) which permits any noncommercial use, distribution, and reproduction in any medium, provided the original author(s) and source are credited.
$95 \%$ of respondents said they had never given such substances to their children. They also declared they wanted more information about the true risks related to uncorrected doping-substances intake. In conclusion, it appears necessary to adopt measures of information and prevention to reduce the diffusion of this dangerous phenomenon.

\section{Introduction}

Doping, or the non-therapeutic use of substances aimed at artificially improving sports performance, is a phenomenon that is spreading both in the sporting world and in the social reality for the interests, the environmental pressures of the sports economic system, but also the search for victory and the search for the emulation of aesthetic and behavioral models imposed by the current society. This has facilitated the placing on the illegal (above all, web) market of doping substances and not facilitating the massive and difficult to quantify diffusion in amateur sports practices. ${ }^{1}$ From some studies conducted in the amateur field on the use of doping substances, there are reasons for improving performance, reducing recovery time after training and increasing muscle mass in the shortest possible time. ${ }^{2}$ In the psychological field, other studies show the use of doping substances to reduce anxiety before a sports performance, to improve the physical appearance, to appear stronger and safer. ${ }^{3}$ Finally, the use of doping substances has often been found associated with the abuse of so-called recreational drugs (such as cannabis, cocaine, amphetamine and alcohol) ${ }^{4}$ and again, with low academic or academic performance and low self-esteem. ${ }^{5}$ Recent studies show that the phenomenon is growing and register an increase in the abuse of doping substances and not among Italian athletes. ${ }^{6}$ According to the Ministry of Health, food supplements are defined as food products intended to supplement the common diet and which are a concentrated source of nutrients, such as vitamins and minerals, or other substances having a nutritional or physiological effect, in particular, but not exclusively, amino acids, essential fatty acids, fibers and extracts of plant origin in pre-dosed forms. ${ }^{7}$ Those who practice physical activity must find a correct and balanced diet, leaving to the attending physician the discretion to enrich it with Vitamins, Mineral salts or other supplements able to prevent or cure any diseases because an incongruous intake of supplements is harmful and dangerous for health. The intake of vitamins and/or food supplements, where there is no particular need, can lead to the appearance of side effects; this can occur if, for example, the integrator is taken in different ways and dosages compared to the therapeutic ones. ${ }^{8}$ Among the most common adverse effects, those reported in the scientific literature are: aggressiveness, headache and 
increased systolic pressure. The use of food supplements is constantly growing in all developed countries. Moreover, often these products not banned for doping, are purchased through parallel channels or through clandestine importation from countries in which adequate controls on the purity of active ingredients are not in force, on the presence of substances (not declared on the label) prohibited for doping and/or on the presence of pesticide residues and/or heavy metals in herbal products thus increasing the risk of recruitment. ${ }^{9}$

\section{Materials and Methods}

In order to obtain data about the epidemiology of the amateur doping and the risks related to the problems, we conducted an online-survey through Google forms, in the period from January to September 2018. We proposed the same questionnaire, composed by 12 articles, also on paper and we administered it, individually and anonymously, in many gyms in Palermo and Trapani (Sicily, Italy). The sample examined consists of 976 people aged between 14 and $65(47.3 \%$ of them are women and $52.7 \%$ are men).

We extrapolated the data through the questionnaires by creat- ing a worksheet on Microsoft Excel and subsequent descriptive statistical analysis (Microsoft Excel).

This survey is included in the Prevention and Information about New and Rape Drugs, Addiction and Amateur Doping project, sponsored by the University of Palermo and the Health Department of the Sicilian Region.

\section{Results}

The examined sample consists of 976 people aged between 14 and 65 (Figure 1A): $47.3 \%$ of them are women and 52.7\% are men (Figure 1B).

Before proceeding with the questions, we evaluated the employment level of the sample: $56 \%$ of them are students, $36 \%$ workers, $8 \%$ unemployed (Figure 2).

We asked them if they practiced or had ever practiced sports and, possibly, what kind of sports activity (Figure 3): 92.8 of them claim to have practiced sports and the major activities are $35 \%$ gym, $15 \%$ fitness, $8 \%$ football and $7 \%$ swimming.

We asked them if they ever took on substances to improve their athletic performances: $25.8 \%$ of them answered affirmatively and

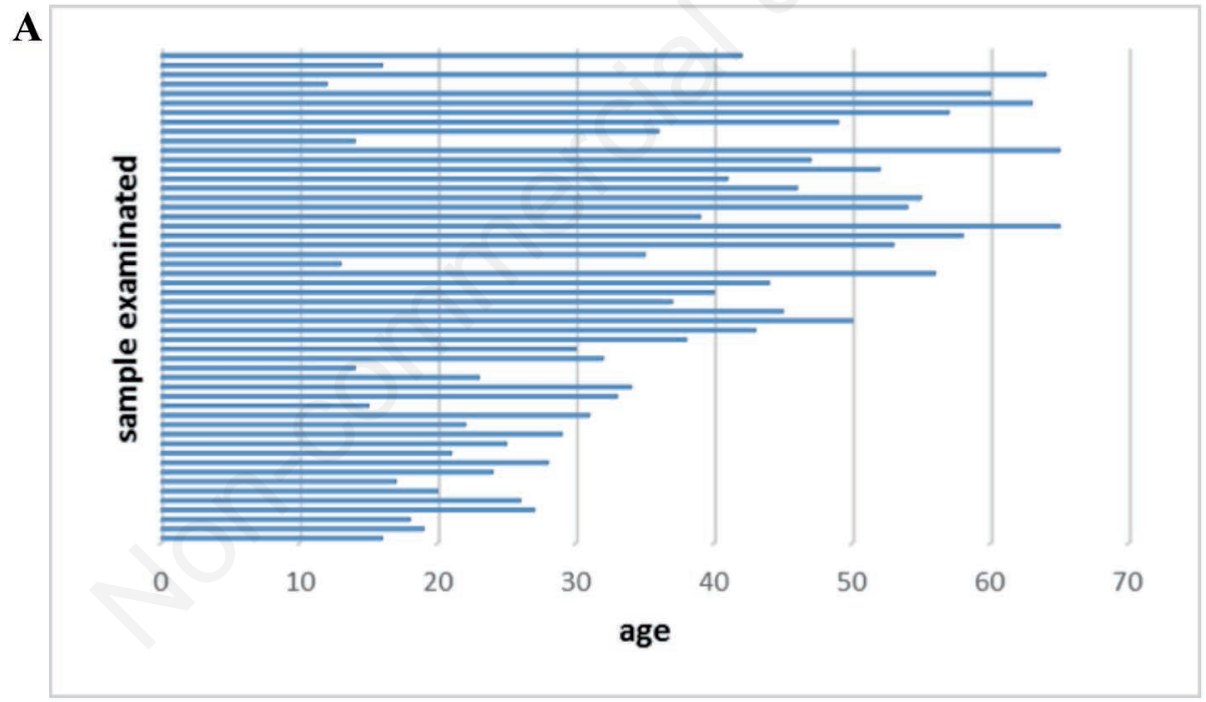

B

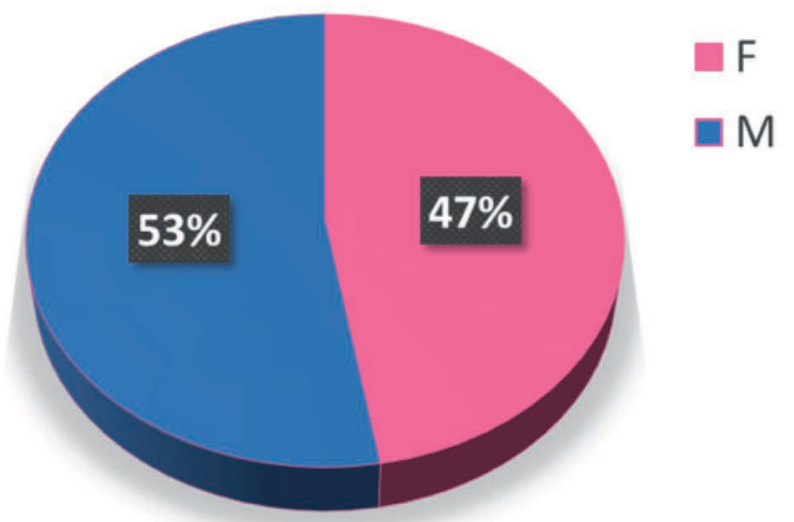

Figure 1. Age and sex of the sample. 
they declared to take on protein, amino acids but also ephedrine, caffeine, aspirin (Figure 4).

Moreover, $34.6 \%$ of them declares to have hired those substances on regular basis. It can be seen from Figure 5 .

With the purpose to research the main supply channel, we asked the sampled subjects where they had purchased these products. They bought this substances in sporting stores $(32.2 \%)$, in pharmacy without prescription $(26.8 \%)$, on internet sites $(22.8 \%)$, in gyms $(10.7 \%) ; 7.5 \%$ of them answered that they bought substances in other places (Figure 6).

\section{OCCUPATION}

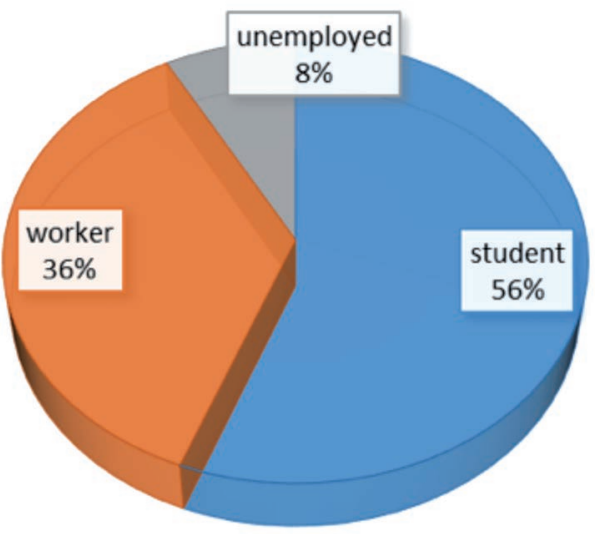

Figure 2. Employment level of the sample.

$\mathbf{A}$

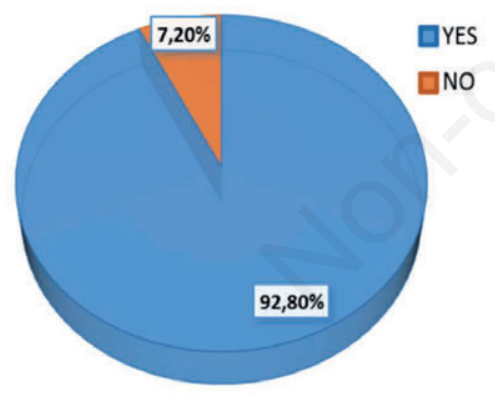

B
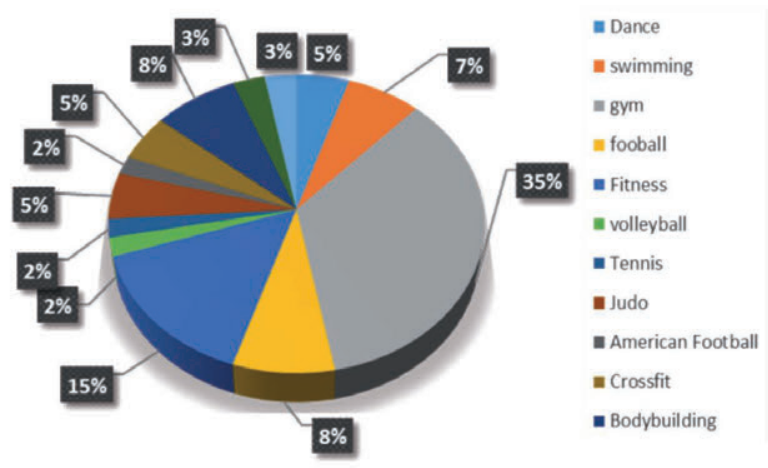

Figure 3. Percentages of people who practice sport (A) and percentages of their sport activities (B).
Thanks to underlying graph (Figure 7), it is possible to see which figures have proposed the employment of doping substances to the respondents. Furthermore, $47 \%$ of them declared that training companions have proposed to them to take doping-substances (stanazolol, tamoxifen, testosterone, erythropoietin, etc.), but also coaches $(33 \%)$ and/or responsible of sports societies $(7 \%)$, team doctor $(7 \%)$, massage therapist $(6 \%)$.

We asked them if they knew what doping is and $95.9 \%$ said: it was about taking substances in order to improve their sports performance.

We have also created a strategic question to assess the degree of awareness of doping substances: Caffeine - Cocaine - Ephedrine - Cannabis - Amino acids - Creatine - Carnitine - Vitamins - EPO

- Testosterone - Nandrolone - Growth hormone (GH) - Aspirin Paracetamol - Codeine - Amphetamine: Do you know if the listed substances can harm your health?

93.7\% answered yes but it is alarming that, even if it is a small percentage, $6.3 \%$ answered no. $48 \%$ of them also believe that these substances, if taken for a long time, are not harmful.

$20 \%$ of respondents also believe that these substances do not need to be taken after checking and prescription.

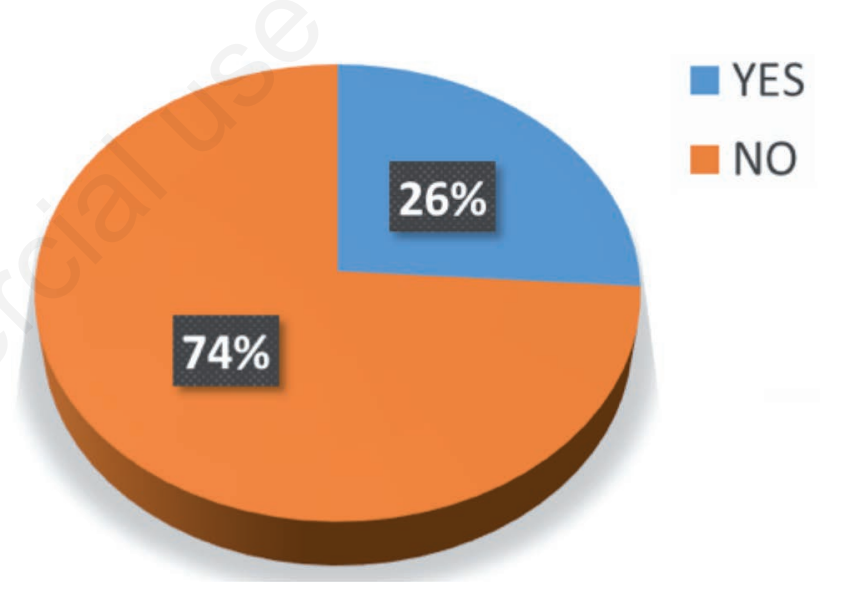

Figure 4. Percentages of people who took substances to improve their performances.

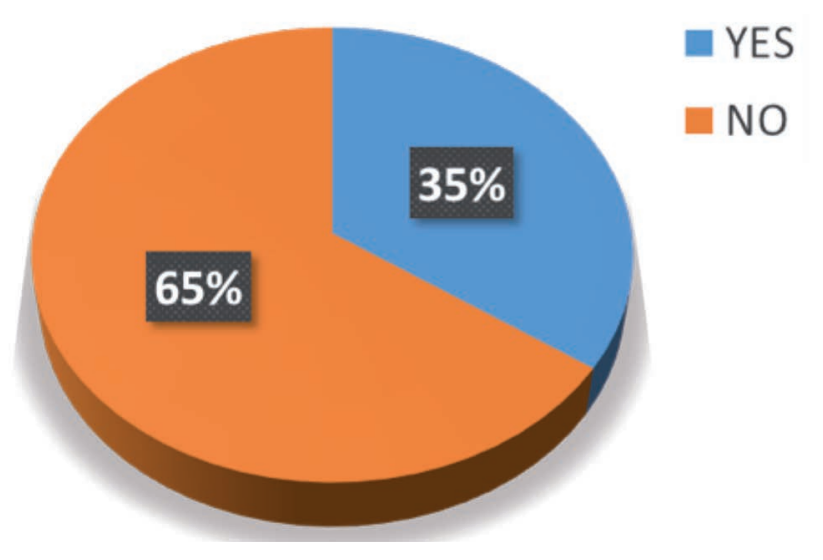

Figure 5. People who declared to take substances on a regular basis. 


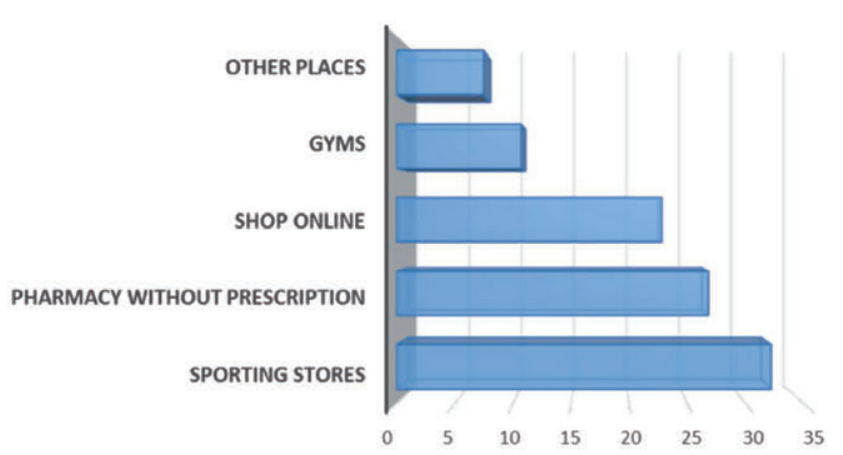

Figure 6. Places where the respondents buy substances.

Finally, $16.8 \%$ of interviewed claimed that is right to take substance with the purpose to improve their performances. However, when we asked them if they would ever have taken substances to their children, $95.8 \%$ of them answered absolutely not. What is also crucial is that they declared $(81 \%)$ to want more information about the real dangers related to uncorrected doping-substances intake.

\section{Discussion and Conclusions}

The data obtained from this research suggest the expansion of behaviors correlated to amateur doping; these behaviors are not to be underestimated as they can lead to serious damage to people's health.

The most alarming figure is the spread of the intake of supplements among amateurs, which often happens through unconventional channels and which escape the laws of the Ministry of Health; this is fueled by the belief that sports supplements are a valid alternative to the use of doping substances to influence sports performance. Through appropriate prevention and information campaigns it is essential both to clarify the actual definition of supplements and to regulate in an appropriate manner (from a legislative point of view) the distribution channels of such products, especially checking the illegal market, and making sure that the doses declared on the label reflect the real ones.

So, it is fundamental to: i) continue the investigation by expanding the sample of individuals analyzed; ii) act promptly by implementing prevention and information systems in gyms and other facilities (such as schools); iii) train coaches and those who have direct contact with those who practice physical exercise.

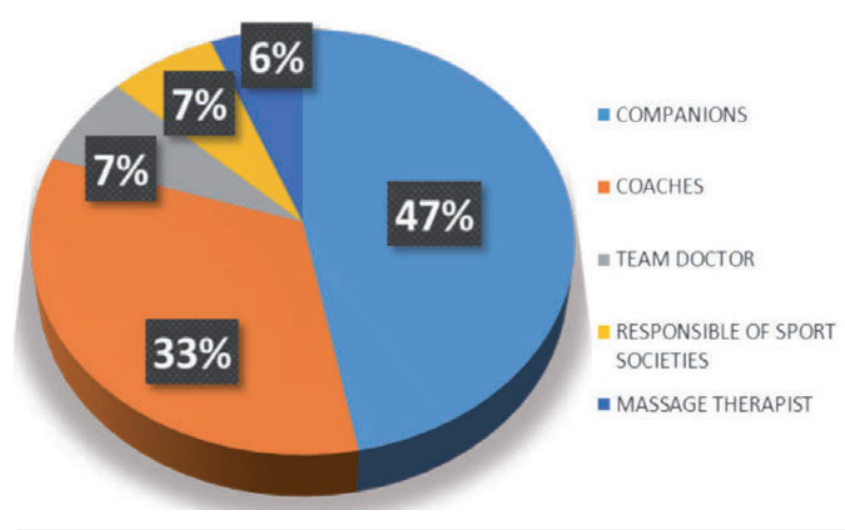

Figure 7. People who proposed them to intake doping substances.

\section{References}

1. Potenza MN, Wareham JD, Steinberg MA, et al. Correlates of at-risk/problem internet gambling in adolescents. J Am Acad Child Adolesc Psychiatry 2011;50:150-9.

2. Backhouse SH, Whitaker L, Petróczi A. Gateway to doping? Supplement use in the context of preferred competitive situations, doping attitude, beliefs, and norms. Scand J Med Sci Sports 2013;23:244-52.

3. De Mei B, Cadeddu C, Luzi P, Spinelli A. Movimento, sport e salute: l'importanza delle politiche di promozione dell'attività fisica e le ricadute sulla collettività. Rapporti ISTISAN 18/9. Roma: Istituto Superiore di Sanità; 2018.

4. Venturella F, Cancellieri G, Catania F, Liga AV. Amateur doping: a survey among Sicilian people. In: Abstracts of the 91st SIBS National Congress: the role of the Italian Society for Experimental Biology in the Italian research. Ancona, Italy, 910 November 2018. J Biol Res 2018;91(s1):7920. p 14.

5. Venturella F, Cancellieri G, Giammanco M, Liga AV. Statistical analysis of a survey about diffusion of binge drinking and drunkorexia among students in Palermo. J Biol Res 2018;91:7579.

6. Venturella F, Liga AV, Catania F, Cancellieri G. Statistical analysis about diffusion of exercise addiction in Sicily. In: Abstracts of the 91st SIBS National Congress: the role of the Italian Society for Experimental Biology in the Italian research. Ancona, Italy, 9-10 November 2018. J Biol Res 2018;91(s1):7920. p 14.

7. La Torre G, Limongelli F, Masala D, et al. Conoscenze, attitudini e comportamenti nei confronti del doping e degli integratori alimentari in un campione di atleti del centro-sud Italia. Med Sport 2001;54:229-33.

8. Brunton L, Chabner BA, Knollman B. Goodman \& Gilman's: the pharmacological basis of therapeutics. 12th ed. New YorkLondon: McGraw-Hill; 2006. pp 78-80.

9. Catlin DH, Fitch KD, Ljungqvist A. Medicine and science in the fight against doping in sport. J Intern Med 2008;264:99-114. 